\title{
Delamination Assessment of FRP Composite Plate Using Natural Frequencies
}

\author{
S Sanyasi Naidu, Ch Ratnam
}

\begin{abstract}
The most frequent failure mode of composite plates is delamination. Deboning between the adjacent layers at a particular region of the multilayered composite plate is consider as delamination. It is due to a defect in the manufacturing practice or can be caused by service time conditions, for example, impact by foreign objects. Overall Stiffness of the composites reduces due to delamination.

This paper presents the effect on natural frequency due to the delamination of the fiber-reinforced plastics (FRP) composites. In the finite element method, delamination is implemented as a VCCT or cohesive zone method, but in this article, delamination modeled as an open area in the interface layer in ANSYS ACP (pre).Numerical and experimental modal analysis is performed to delaminate as well as intact composite plates. Extract modal parameters like natural frequencies and mode shapes from the modal analysis. The results of the present paper compare among the existing simulation results and observe that good agreement between them. also, study the variation of frequencies with an increase of delamination. The new proposed modeling of delamination is simple and gives accurate results. This method is also used tostudy the delamination effect in composite plates.
\end{abstract}

Keywords : Delamination, Natural frequency, Composite plate, Modal analysis

\section{INTRODUCTION}

In the current period, composite resources are supplanting conservative metals in aerospace, automotive, civil and marine industries. The most significant reward of composites is high strength to weight ratio, low weight, and corrosion resistance. These fabric types are however prone to delamination and thus necessitating the early recognition of the flaw before it initiates into a critical fault. Cost-effective and dependable damage discovery is critical for the consumption of composite resources. Health monitoring of such structure is extremely necessary to stop sudden breakdown.The most common failure mode of composite plates is delamination. Debonding between the adjacent layers at a particular region of the multilayered composite plate is consider as delamination. It reduces the compressive strength of the laminated composites. It takes place inside of the composite layers, so without breaking it is complex to locate the delamination existence in the multilayered

Revised Manuscript Received on December 30, 2019.

* Correspondence Author

S Sanyasi Naidu*, Department of Mechanical Engineering, MVGR College of Engineering(A), Vizianagaram, India.

Prof. Ch. Ratnam, Department of Mechanical Engineering, AUCE(A), Andhra University, Visakhapatnam, India.

(C) The Authors. Published by Blue Eyes Intelligence Engineering and Sciences Publication (BEIESP). This is an open access article under the CC BY-NC-ND license (http://creativecommons.org/licenses/by-nc-nd/4.0/) composites. Hence, the forecast for delamination in composites is required during the service time of composites.

The elastic material constants of FRP composites are evaluated using different techniques like vibration properties[1, 2], the full field measurement of the surface deformations of plates under the flexural loads (interferometric techniques)[3], Digital Image Correlation technique [4]. The elastic constants of the composite plate are determined by the inversion method, experimental data is used to Lamb wave transmission and a curve fitting algorithm based on the Nelder-Mead simplex method[5].

Vibration-based damage detection methods[6,7,12,13,14] using modal parameters which are easily and continuously extract from the oscillations of a working structure shows potential in structural health monitoring (SHM). The damage in the structure reduces the local stiffness, of the structures. Modal characteristics of plates such as natural frequencies, mode shapes, modal curvature, modal strain energy, and damping ratios, etc. Modal parameters are more sensitive to this change of stiffness, which is prompt to measure the damage location.

Delamination can be modeled in various methods for modal analysis of multilayered composites. Delamination is implemented using 9 noded quadrilaterals MITC9 element in the Carrera Unified Formulation framework[8], the delamination [9] is simulated as an inter space of $0.02 \mathrm{~mm}$ between the layers of the multilayered composite plate. Virtual elements [11] are used to model the area of delamination to avoid element penetration.

In this dissertation, a 3D model of finite elements for laminated composite plates includes inside delamination incorporated as the open area in the interface layer in ANSYS ACP (pre).The composite plates are modeled by considering individual fiber orientations lamina. Finite element modal analysis is conceded for intact and delaminated composites under free-free boundary conditions. Modal parameters like natural frequencies and mode shapes of the intact and delaminated composites are extracted. The numerical results are validated with accessible literature. The most important thing of the present paper is the accomplishment of the delamination model as an open area in the interface layer in ANSYS ACP (pre).

\section{DELAMINATION MODELING AND VERIFICATION}

\section{Composite plates:}

Five multi-layered glass fiber- reinforced epoxy square plates are considered for finite element simulations. The volume of each composite plate 


\section{Delamination Assessment of FRP Composite Plate Using Natural Frequencies}

is $225.5 \times 225.5 \times 2.05 \mathrm{~mm}^{3}$ with the stacking sequence of $[0 / 90 / 0 / 90]_{s}$. Out of five plates, one is intact and named with $\mathrm{O}$, the remaining composites are named as $\mathrm{A}, \mathrm{B}, \mathrm{C}, \mathrm{D}$, respectively, are delaminated with different areas of delamination. Delamination area is replicated as an inter space, or disconnection, of $0.02 \mathrm{~mm}$ among the fourth and the fifth layers from the top of the composite plate, but in the present work, delamination is created as an open area in the interface layer using workbench ACP (pre).

Delamination center is common as shown figure1. For all the delaminated plates, but delamination area is different. The coordinates of the delamination position are $\mathrm{x}=163.5 \mathrm{~mm}, \mathrm{y}=163.5 \mathrm{~mm}$ and $\mathrm{z}=1.28125$. The areas of delamination of composite plates of A, B, C and D are 11.275 x 11.275, 33.825 x 33.825, 56.375 x 56.375 and 78.925 x $78.925 \mathrm{~mm}^{2}$, respectively. Theelastic constants of the composites fornumerical analysis are $\mathrm{E}_{1}=37780 \mathrm{MPa}, \mathrm{E}_{2}=$ $\mathrm{E}_{3}=$
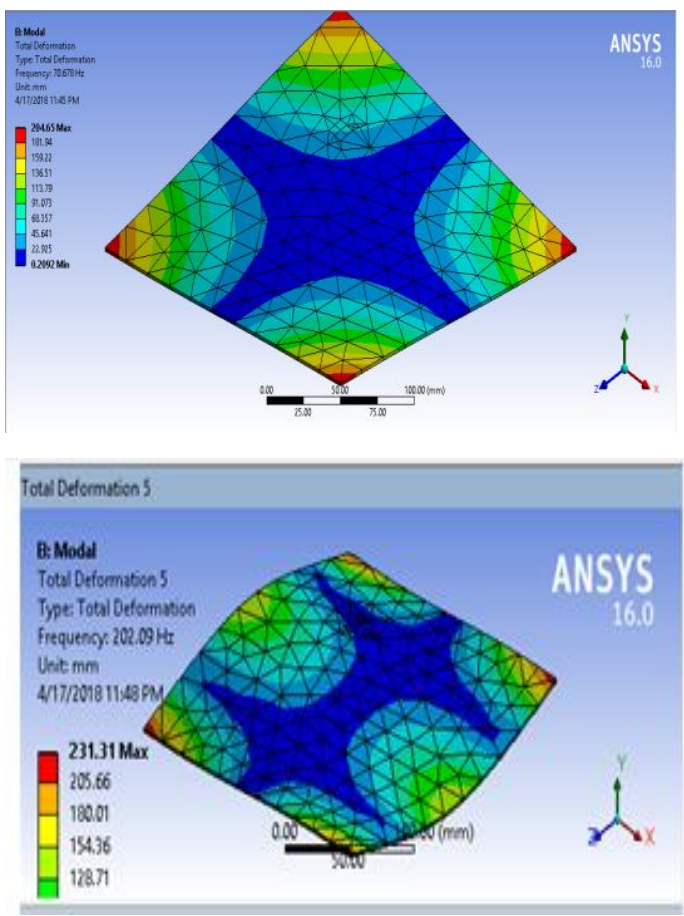

$10900 \mathrm{MPa}, \mathrm{G}_{12}=\mathrm{G}_{13}=\mathrm{G}_{23}=49100 \mathrm{MPa}, \mathrm{v}_{12}=\mathrm{v}_{13}=0.3, \mathrm{v}_{23}$ $=0.11$ anddensity $(\rho)=1813.9 \mathrm{~kg} / \mathrm{m}^{3}$, Yam et.al. [10].

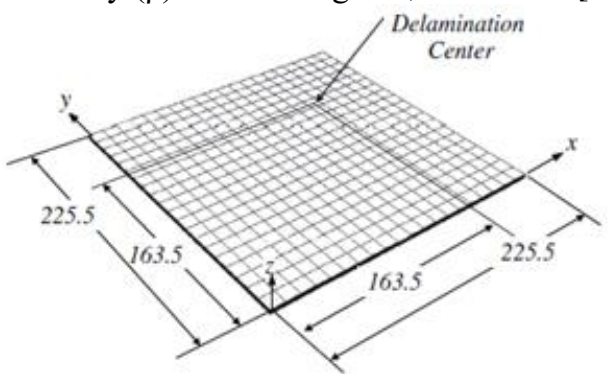

Fig. 1. Meshed form of the composite plate with delamination center.[9]

Finite element modal analysis is done for specified plates and the results are shown below.

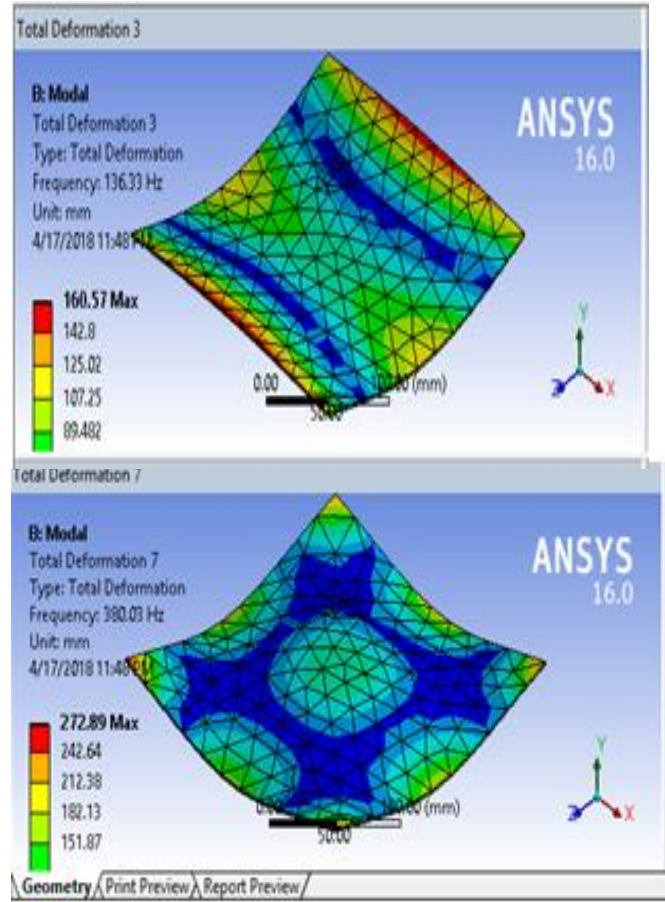

Fig.2. Mode shapes of plate $B$ of a composite plate

Table1:FEM results of fundamental frequencies in $\mathrm{Hz}$ for the composite plates.

\begin{tabular}{|c|c|c|c|c|c|}
\hline & Plate $\mathrm{O}$ & & & & \\
\hline $\begin{array}{l}\text { Mode } \\
\text { No. }\end{array}$ & & $\begin{array}{c}\text { Delamination (A) } \\
11.275 \times 11.275 \mathrm{~mm}^{2}\end{array}$ & $\begin{array}{c}\text { Delamination (B) } \\
33.825 \times 33.825 \mathrm{~mm}^{2}\end{array}$ & $\begin{array}{c}\text { Delamination (C) } \\
56.375 \times 56.375 \mathrm{~mm}^{2}\end{array}$ & $\begin{array}{c}\text { Delamination (D) } \\
78.925 \times 78.925 \mathrm{~mm}^{2}\end{array}$ \\
\hline
\end{tabular}

Published By:

Blue Eyes Intelligence Engineering 


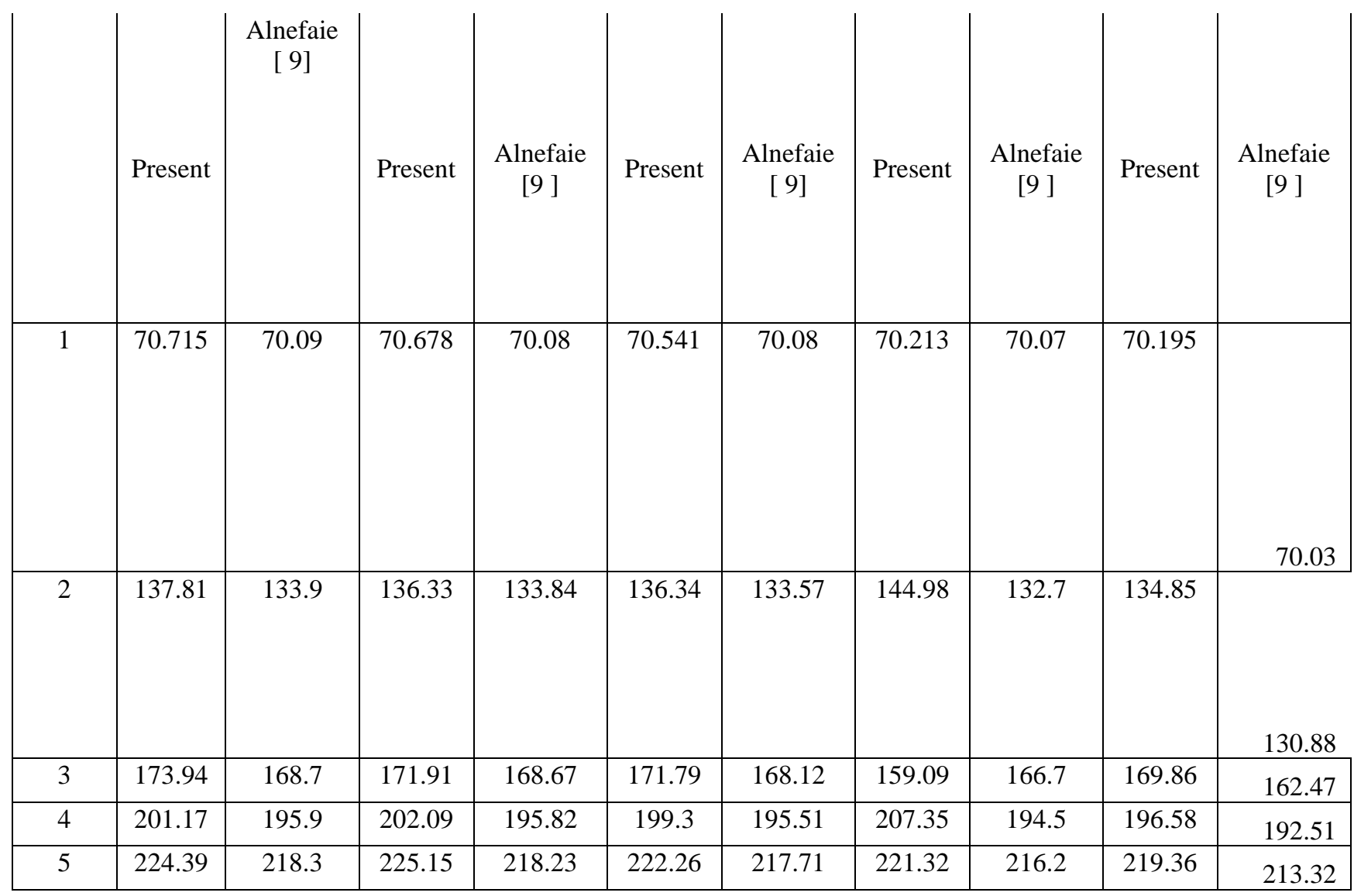

\section{FINITE ELEMENT AND EXPERIMENTAL MODAL ANALYSIS:}

Finite element Modal Analysis: The frequencies of the laminated plates with different delamination sizes are computed using a simulation model developed in ANSYSworkbench ACP (pre).

The composite plate is modeled using ANSYS ACP as per the required stacking sequence and dimensions. The numerical analysis is carried out for the intact laminated composite plates to find the natural frequencies.

The Glass/epoxy composite plate $(250 \times 70 \times 6)$ with fiber orientation is $\left[0 \% / 90^{\circ} / 0^{\circ} / 90^{\circ}\right]_{\mathrm{s}}$ is consider for analysis. The delamination is located at center of plates B and C are 30x30 $\mathrm{mm}^{2}$ and $50 \times 50 \mathrm{~mm}^{2}$. Thematerial constants of the composite plates fornumerical analysis areE $_{1}=45 \mathrm{GPa}, \mathrm{E}_{2}=\mathrm{E} 3=10$ $\mathrm{GPa}, \mathrm{G} 12=\mathrm{G}_{13}=5 \mathrm{GPa}, \mathrm{G}_{23}=3.84 \mathrm{GPa}, \mathrm{v}_{12}=v_{13}=0.3, v_{23}=$ 0.33 and $\rho=1830 \mathrm{~kg} / \mathrm{m}^{3}$.

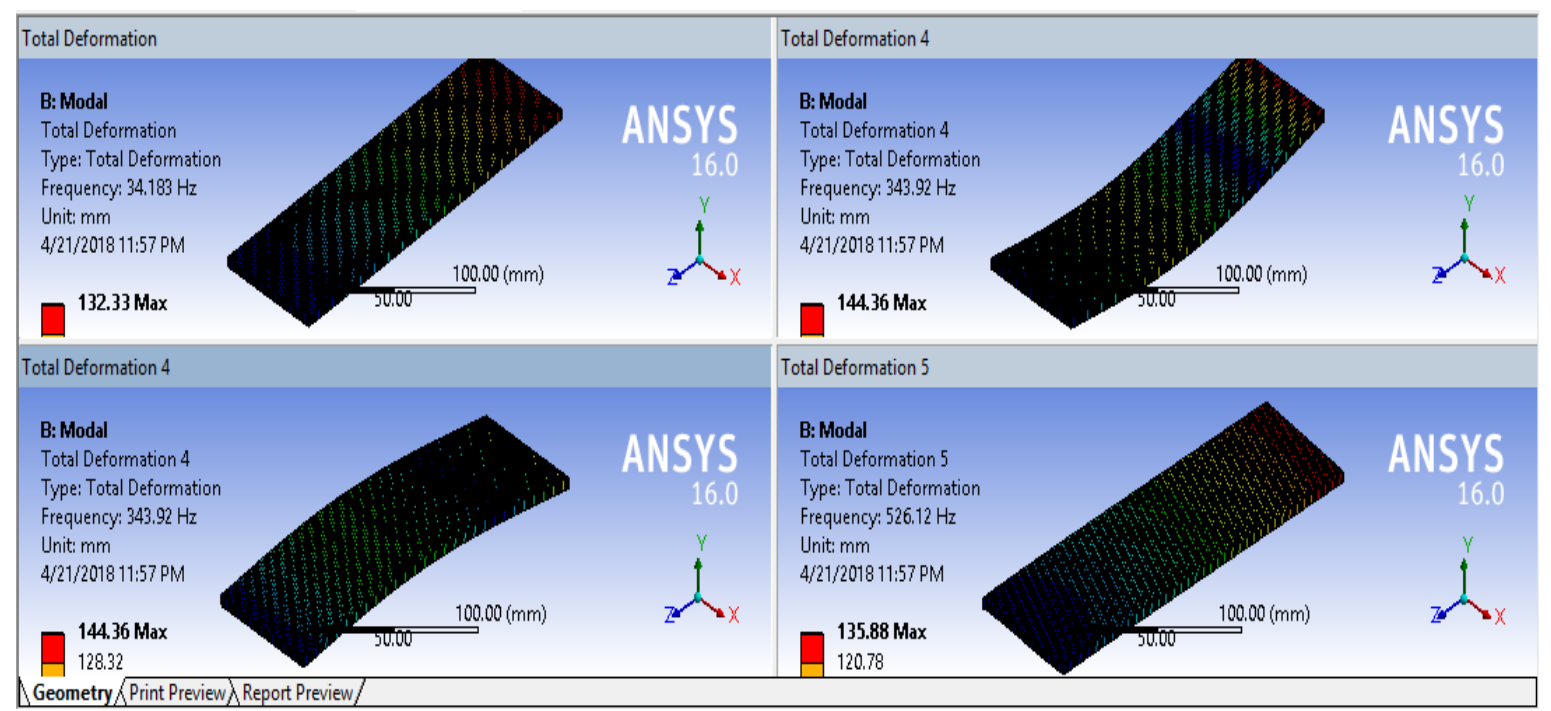

Fig.3. Intact composite plate First four Mode Shapes 


\section{Delamination Assessment of FRP Composite Plate Using Natural Frequencies}

\section{Materials and Composites Preparation:}

The experimental modal analysis is done on the composites with the stacking sequence $[0 / 90 / 0 / 90]_{s}$. The composites are fabricated by hand lay-up technique. Three composite samples of dimensions $250 \mathrm{~mm} \times 70 \mathrm{~mm} \times 6 \mathrm{~mm}$ are fabricated, one is intact and two specimens are delaminated

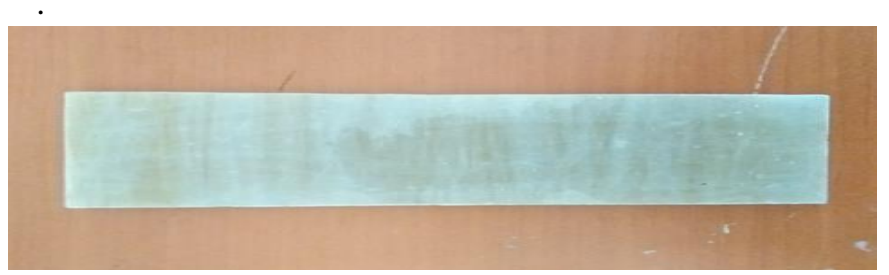

Fig. 4: Intact composite plate of size $250 \times 70 \mathrm{~mm}^{2}$ with areas at centers are $30 \times 30 \mathrm{~mm}^{2}$ and $50 \times 50 \mathrm{~mm}^{2}$ respectively.Artificial delamination is produced by Teflon tape film of a thickness of $25 \mu \mathrm{m}$ in the middle of the planes in the period of fabrication of composites

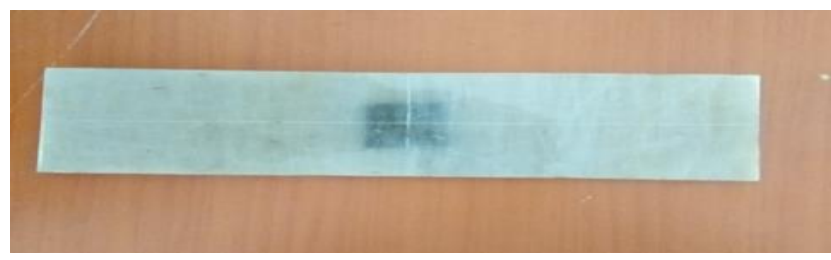

Fig. 5: With Delaminated Area of size $30 \times 30 \mathrm{~mm}^{2}$

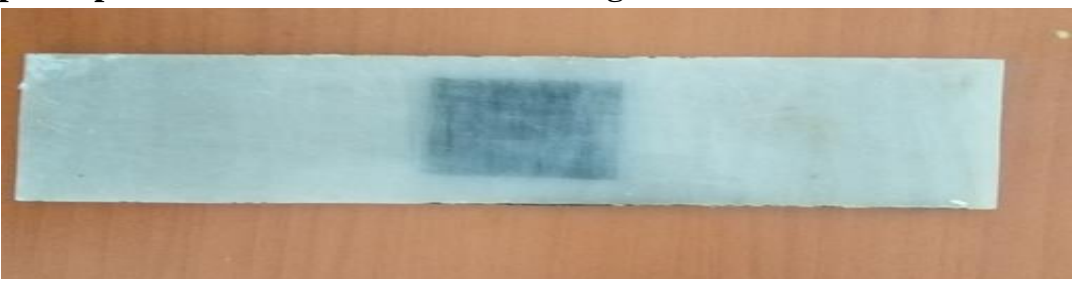

Fig. 6: With Delaminated Area of size $50 \times 50 \mathrm{~mm}^{2}$

Using FFT Analyzer and impact hammer experimental modal analysis is performed to evaluate the fundamental frequencies of the composites intact and delaminated plates.

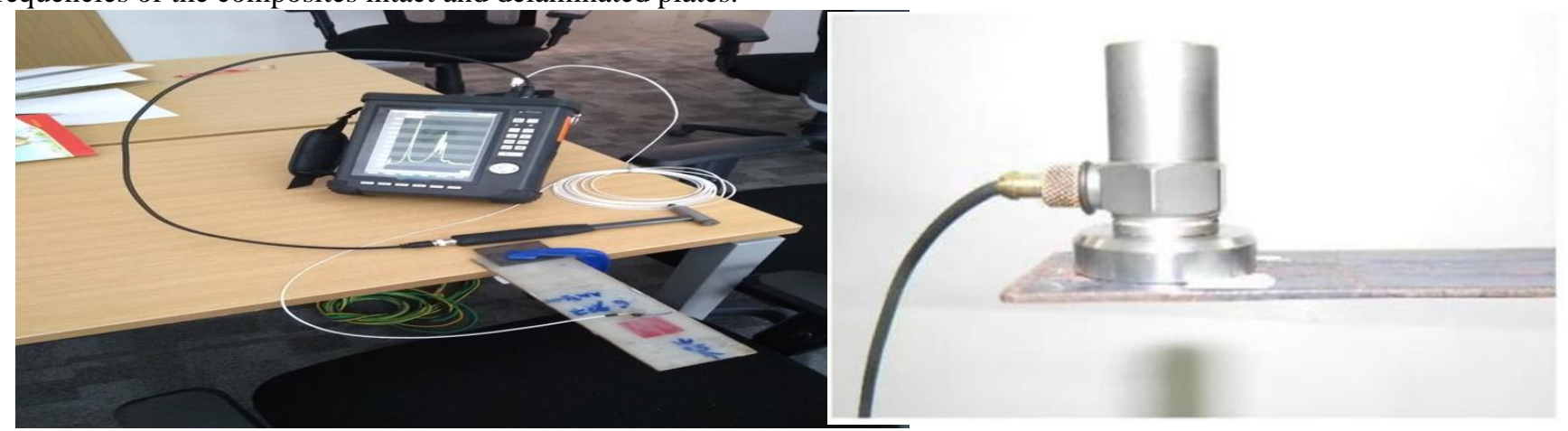

Fig.7: Experimental setup

\section{Experimental procedure:}

The experimental procedure is followed for the extraction of natural frequencies of composite samples.

○ Fasten the composite plate as a cantilever.

○ Connect all the accessories (impact hammer, FFT analyzer) to user interference

o The composite is excited with an impact hammer.

- Perform the experimental modal analysis with Fast Fourier Transformation (FFT) on the composite to determine the natural frequency and mode shape.
- The natural frequencies are obtained from Frequency Response Function (FRFs) by identifying the peaks and these frequencies are considered as natural frequencies when the coherence function corresponding to the frequency is greater than 0.85 those values are considered as natural frequencies.

○ Perform the impact testing at all the network points of the composite plate and extract natural frequencies of the samples.

\section{RESULTS AND DISCUSSIONS}

4.1. Finite Element Results:

Finite element modal analysis is performed intact and delaminates composite plates and the results are tabulated below.

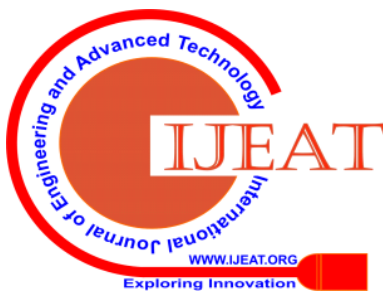




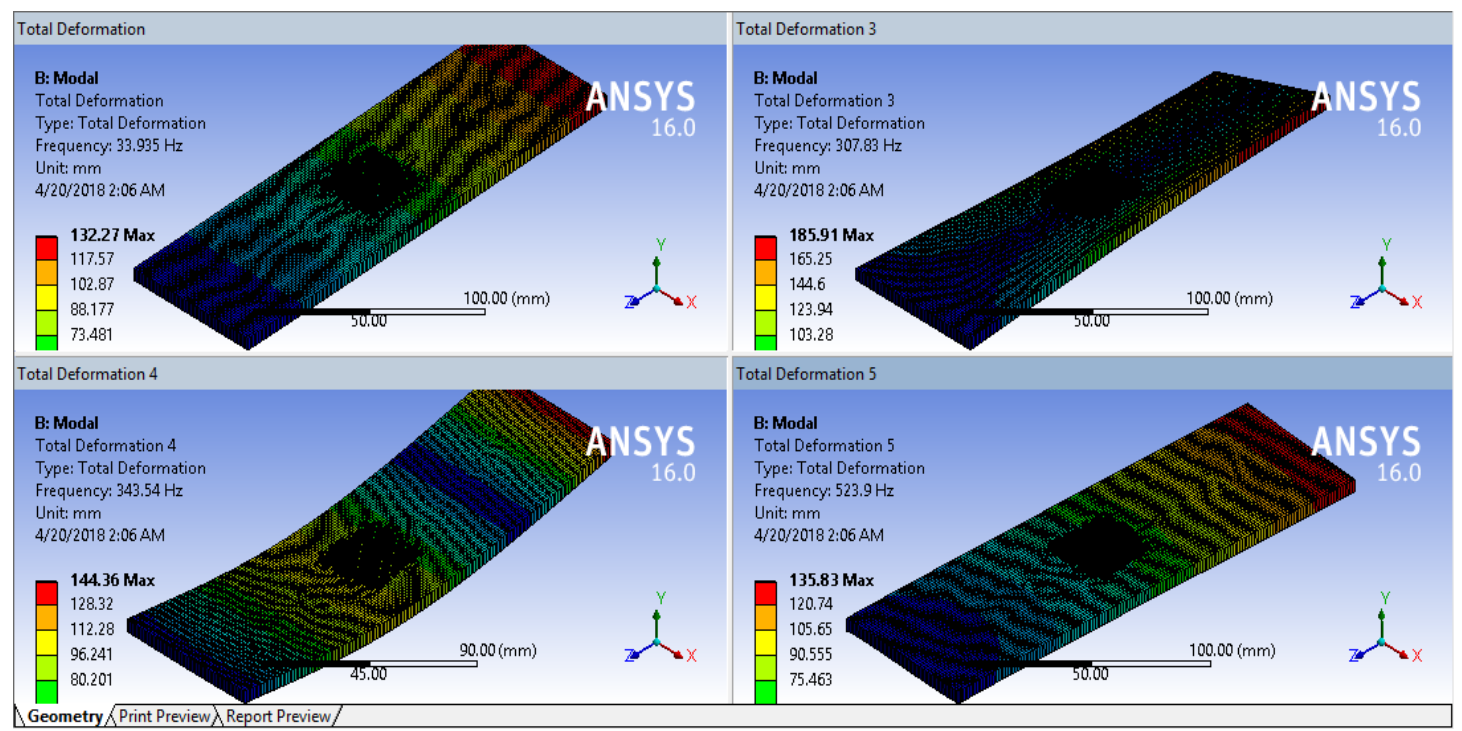

Fig.8. Mode shapes of delaminated composite plate $\left(30 \times 30 \mathrm{~mm}^{2}\right)$

Table -2: FEM first three Natural frequencies of composite plates

\begin{tabular}{|c|c|c|c|}
\hline & \multicolumn{3}{|c|}{ Natural Frequencies (Hz) } \\
\hline $\begin{array}{c}\text { Mode } \\
\text { Number }\end{array}$ & Plate O & $\begin{array}{c}\text { Delamination } \\
\text { area } \\
30 \times 30 \mathrm{~mm}^{2}\end{array}$ & $\begin{array}{c}\text { Delamination } \\
\text { area } \\
50 \times 50 \mathrm{~mm}^{2}\end{array}$ \\
\hline 1 & 34.183 & 33.935 & 31.98 \\
\hline 2 & 308.03 & 307.83 & 306.19 \\
\hline 3 & 343.92 & 343.54 & 342.34 \\
\hline
\end{tabular}

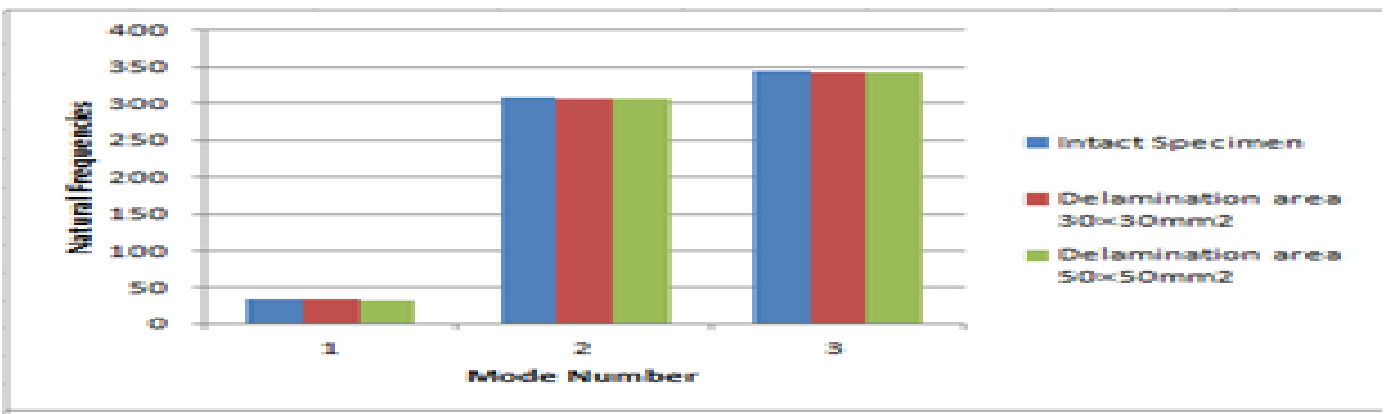

Fig.9 : Mode Number $V_{s}$ Natural Frequencies

\section{Experimental Results:}

Experimental modal analysis performs on the composites using FFT Analyzer, accelerometer and Impact hammer by hammer roving method. 
Delamination Assessment of FRP Composite Plate Using Natural Frequencies

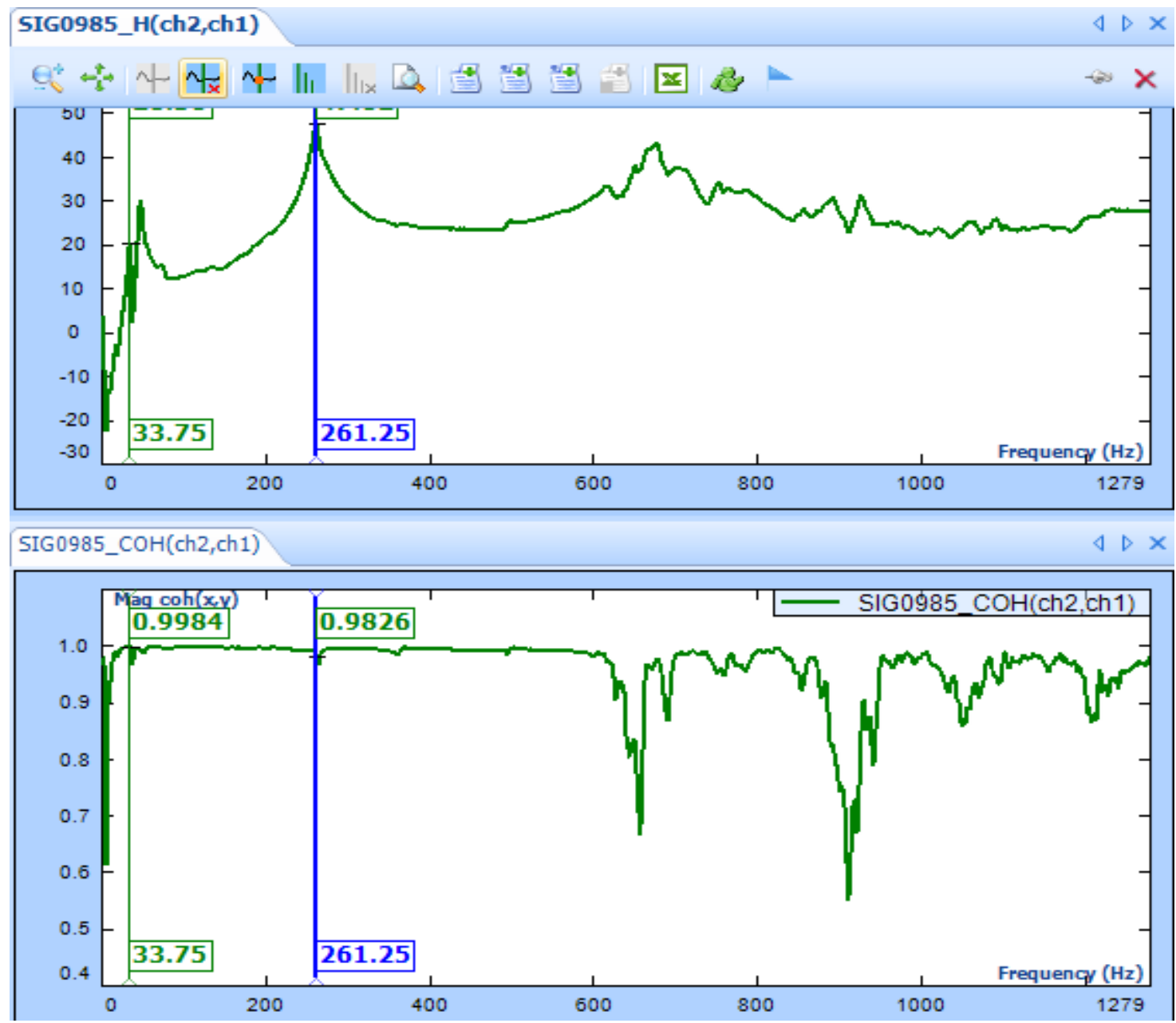

Fig.10. Coherence and FRF windows of FFT analyzer for the intact specimen.

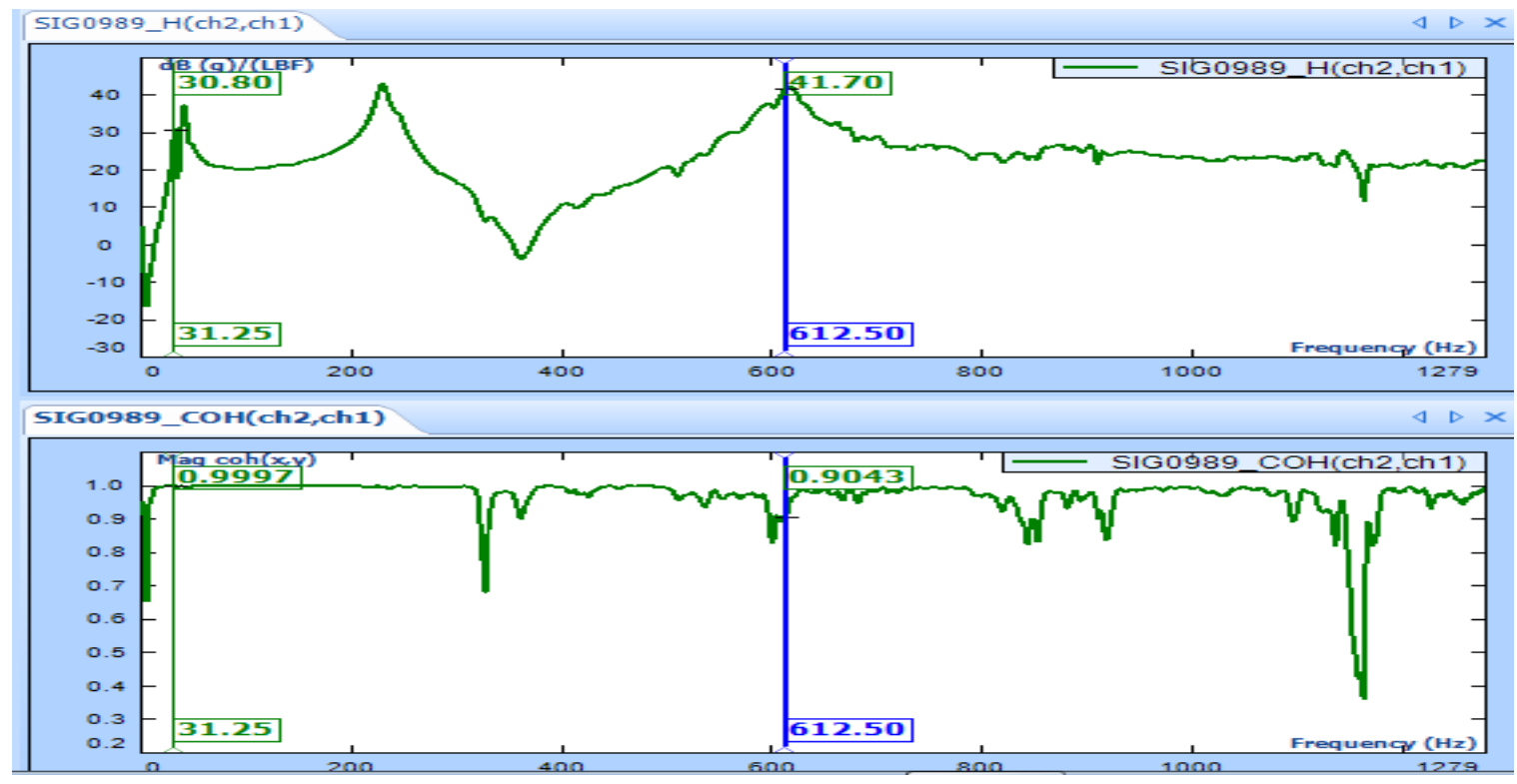

Fig.11. Coherence and FRF windows of FFT analyzer for $50 \times 50 \mathrm{~mm}^{2}$ delamination. 
The consequence of the delamination area on natural frequencies is studied. The variation in the fundamental

Table 3:Experimental Natural Frequencies(Hz)

for the composite plates.

\begin{tabular}{|c|c|c|c|}
\hline & \multicolumn{3}{|c|}{ Natural Frequencies(Hz) } \\
\hline Mode & $\begin{array}{c}\text { Without } \\
\text { Delamination }\end{array}$ & $\begin{array}{c}\text { Delamination } \\
\text { 30x30 } \mathrm{mm}^{2}\end{array}$ & $\begin{array}{c}\text { Delamination } \\
50 \times 50 \mathrm{~mm}^{2}\end{array}$ \\
\hline 1 & 33.75 & 32.508 & 31.25 \\
\hline 2 & 261.25 & 260.75 & 228.75 \\
\hline 3 & 686.25 & 661.25 & 612.56 \\
\hline 4 & 968.75 & 958.45 & 903.75 \\
\hline
\end{tabular}

The following figure shows the variation of Natural frequencies for the first four modes with different sizes of delamination areas. frequency with different sizes of delamination are shown in table:3

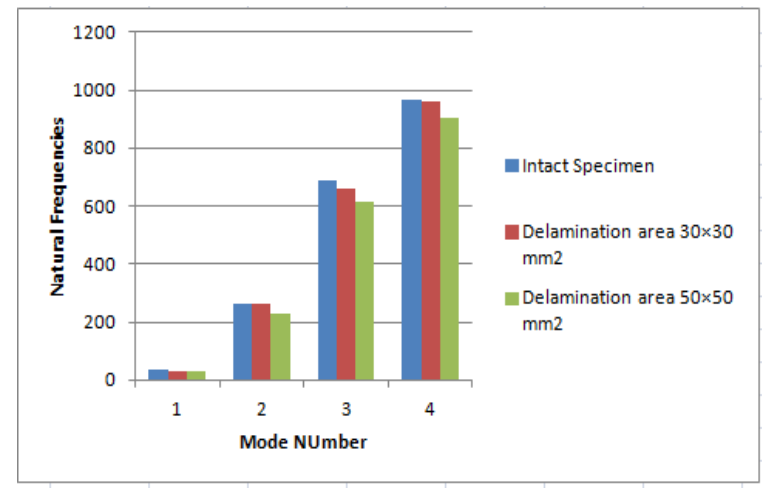

Fig.12: Mode Number $V_{s}$ Natural Frequencies

Table 4. Percentage change in Natural frequency for $30 \times 30 \mathrm{~mm}^{2}$ and $50 \times 50 \mathrm{~mm}^{2}$ delamination.

\begin{tabular}{|c|c|c|c|c|c|}
\hline & \multicolumn{5}{|c|}{ First Three natural frequencies (Hz) } \\
\hline Mode & $\begin{array}{c}\text { Without } \\
\text { Delamination }\end{array}$ & $30 \times 30 \mathrm{~mm}^{2}$ & $\begin{array}{c}\text { \% change } \\
\text { in } \\
\text { frequency }\end{array}$ & $50 \times 50 \mathrm{~mm}^{2}$ & $\begin{array}{c}\% \text { change } \\
\text { in } \\
\text { frequency }\end{array}$ \\
\hline 1 & 33.75 & 32.5 & 1.25 & 31.25 & 2.5 \\
\hline 2 & 261.25 & 260.75 & 1.6 & 228.75 & 14.7 \\
\hline 3 & 686.25 & 661.25 & 3.6 & 612.5 & 10.7 \\
\hline
\end{tabular}

\section{Comparison of the Numerical and Experimental frequencies:}

The natural frequencies of both Finite element and experimental results maintain consistency. The first two experimental values are tabulated below, both numerical and frequencies are observed the good agreement.

Table5 FEM and Experimental Natural frequencies

\begin{tabular}{|c|c|c|c|c|c|c|}
\hline \multicolumn{2}{|c|}{ Experiment Results(Natural Frequency(Hz)) } & \multicolumn{3}{|c|}{ FEA Results(Natural Frequency(Hz) } \\
\hline $\begin{array}{c}\text { Mode } \\
\text { Number }\end{array}$ & $\begin{array}{c}\text { Plate } \\
\text { O }\end{array}$ & $\begin{array}{c}\text { Delamination } \\
\text { area } \\
30 \times 30 \mathrm{~mm}^{2}\end{array}$ & $\begin{array}{c}\text { Delamination } \\
\text { area } \\
50 \times 50 \mathrm{~mm}^{2}\end{array}$ & $\begin{array}{c}\text { Plate } \\
\text { O }\end{array}$ & $\begin{array}{c}\text { Delamination } \\
\text { area } \\
30 \times 30 \mathrm{~mm}^{2}\end{array}$ & $\begin{array}{c}\text { Delamination } \\
\text { area } \\
50 \times 50 \mathrm{~mm}^{2}\end{array}$ \\
\hline 1 & 33.756 & 32.508 & 31.251 & 34.183 & 33.935 & 31.985 \\
\hline 2 & 261.25 & 260.75 & 228.75 & 308.03 & 307.83 & 306.19 \\
\hline 3 & 686.25 & 661.25 & 612.56 & 343.92 & 343.54 & 342.34 \\
\hline
\end{tabular}

\section{CONCLUSIONS:}

This paper presents the delamination modeling as an open area in the interface layer in WORKBENCHACP (Pre) for composite laminates. The intact and delaminated multi-layer composites have been analyzed by numerical \& experimental modal analysis. The results from the numerical and experimental modal analysis the subsequent conclusions are drawn and discussed as follows:

* As of the comparison study, the results obtained by delamination modeling as the open area in the interface layer in ANSYS-ACP (Pre) are very close to the available published results of the composite plates with and without delamination.

* The magnitude of natural frequencies decreases with increasing the size of delamination, this is due to a decrease of the global stiffness in the damaged composites.

* Numerical results are validated with experimental results, the deviation between the results is less than $5 \%$. 


\section{REFERENCES}

1. Hameed DwechLafta, " Experimental Determination of Elastic Constant of Composite Materials Using Vibration Properties", Journal of Engineering and Development, Vol. 17, No.5, pp. 21-30, 2013.

2. AbdeldjebarRabia,LabbaciBoudjema,Missoum Lakhdar, LahmarLahbib, and Moudden. B, "Dynamic characterization by experimental analysis of a composite beam", Energy Procedia, Vol. 36, PP. $808-814,2013$.

3. LEONARDO. P, "Determining elastic constants of materials with interferometric techniques", Inverse Problems in Science and Engineering, Vol. 14, No. 8, pp. 801-818, 2006.

4. M. Leszek, BilkoPiotr, and E. Kowalska," Determination of Elastic Constants in Brazilian Tests Using Digital Image Correlation" IEEE, pp. 154-157, 2017.

5. K. Lasn, Klauson A., Decultot, andChati," EXPERIMENTAL DETERMINATION OF ELASTIC CONSTANTS OF AN ORTHOTROPIC COMPOSITE PLATE BY USING LAMB WAVES", Mechanics of Composite Materials, Vol. 47, No. 4, pp, 435-446, 2011.

6. Sultan .R, S Guirguiz, YounesM, and E-Soaly," Delamination detection of composite laminates using natural frequency vibration method" International Journal of Mechanical Engineering and Robotics Research, Vol. 01, pp.286-296, 2012.

7. Saket.T, Jamadar .N.I., and Dr. Kivade. S.B.,"Damage Identification in Composite Structures Due to Delamination by Vibration Characteristics- A Review", International Journal of Engineering Science and Innovative Technology Vol. 3, Issue 6, pp. 108-114,2014.

8. S. K. Kumar, Cinefra.M., Carrera , Ganguli Ranjan, and Dineshkumar $\mathrm{H}$,"Finite element analysis of free vibration of the delaminated composite plate with variable kinematic multilayered plate elements", composites: Part B , vol.66, pp. 453-465, 2014.

9. Alnefaie. K., "Finite element modeling of composite plates with internal delamination", composite structures, vol. 90, pp. 21-27, 2009.

10. Yam L.H., Wei. Z, L.Cheng, and W.O. Wong.,"Numerical analysis of multi-layer composite plates with internal delamination",composite structures, vol.82, pp:627-37, 2004.

11. L.H. Yam, Z. Wei, L. Cheng, and W.O. Wong, "Numerical analysis of multi-layer composite plates with internal delamination", Computers and Structures, vol.82, pp. 627-637, 2004.

12. Q. Pizhong, LuKan, Wahyu.L, and Wang. J," Curvature mode shape-based damage detection in composite laminated plates ", Composite Structures, vol. 80, pp. 409-428, 2007.

13. Trung .V.Duy, Ho HuuVinh, Dang HauTrung, CongDinh Cong, andTrungN. Thoi," Damage Detection in Laminated Composite Plates Using ModalStrain Energy and Improved Differential Evolution Algorithm", Procedia Engineering, Vol. 142, pp.181 - 188, 2016

14. R Palazzetti, D Garcia, , I Trendafilova, Fiorini, and Zucchelli , "Vibration based delamination diagnosis and modeling for composite laminate plates" Composite Structures, Vol. 130 , pp. 155-162, 2015.

15. Mechanics of composites, Author Kaw.

16. Mechanics of composites, R.M Jones

17. Baneen. U, Kinkaid N.M, Herszberg, and Guivant, "Vibration based damage detection of a beam-type structure using noise suppression method",Journal of Sound and Vibration, Vol, 331 pp. 1777-1788, 2012.

18. Mohammad-Reza Ashory, Ahmad G.Ghalebahman, and Mohammad KokabiJavad," An efficient modal strain energy-based damage detection for laminated composite plates", Advanced Composite Materials, 2017.

\section{AUTHORS PROFILE}

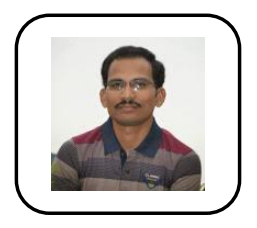

Sanyasi Naidu Sureddi, received his ME Degree from Andhra University College of Engineering(A), Andhra University, Visakhapatnam, India, Currently working as Assistant Professor, Mech. Engg. MVGRCE(A), Vizianagaram, Andhra Pradesh, India. His research interests are Structural Health Monitoring of Composites, Vibrations, and Nanocomposites.

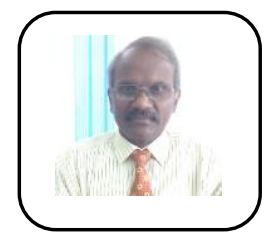

Prof. Ch Ratnam, PhD (IITM), Professor, Andhra University college of engineering, Mechanical Engineering Department, Andhra university, Visakhapatnam, His research interests are Structural Health Monitoring, Vibrational Analysis. 